\title{
An in vitro Study to evaluate the Effects of Various Polymerizing Conditions on the Flexural Strength of Autopolymerizing Resins
}

\author{
${ }^{1}$ Sanjeev Singh, ${ }^{2}$ Abid Z Hussain, ${ }^{3}$ RU Thombare, ${ }^{4}$ BK Motwani, ${ }^{5}$ Shweta Singh, ${ }^{6}$ Sachin B Mangalekar
}

\begin{abstract}
Aim: To investigate the effect of variation in temperature and time intervals on the flexural strength of two brands of autopolymerizing resins polymerized at constant pressure.

Materials and methods: Two autopolymerizing resins RR Cold Cure resin (DPI) and RR-Rapid Repair Powder (Dentsply) were used. A total of 20 samples were fabricated for each group. Samples were polymerized at temperature ranges of $40^{\circ}, 50^{\circ}$, $60^{\circ}$, and $70^{\circ} \mathrm{C}$ and at time intervals of 5,10 , and 15 minutes in the customized curing pot, maintaining pressure of $30 \mathrm{psi}$.
\end{abstract}

Results: Flexural strength was verified using universal testing machine using three-point bending test and was then compared with all samples and also with the samples cured in open air (control group). The samples cured at higher temperature, i.e., $60^{\circ}$ and $70^{\circ} \mathrm{C}$, have shown increased strength than those at $40^{\circ}$ and $50^{\circ} \mathrm{C}$ as well as control group. Time interval of 10 minutes is considered sufficient to increase the strength of the resin, as per the results of this study.

Conclusion: The samples cured under varied condition of time and temperature but under constant pressure showed increased strength than those cured in open air.

Clinical significance: The effect of pressure and temperature has been demonstrated, which could be utilized for enhancing the durability of the prosthesis fabricated from autopolymerized resins.

Keywords: Autopolymerizing resin, Flexural strength, Pressure pot.

How to cite this article: Singh S, Hussain AZ, Thombare RU, Motwani BK, Singh S, Mangalekar SB. An in vitro Study to evaluate the Effects of Various Polymerizing Conditions on

\footnotetext{
${ }^{1,5}$ Reader, ${ }^{2-4,6}$ Professor

${ }^{1,4}$ Department of Prosthodontics, Chhattisgarh Dental College and Research Institute, Rajnandgaon, Chhattisgarh, India

${ }^{2}$ Department of Prosthodontics, Taibah University, Madinah Al Munawara, Kingdom of Saudi Arabia

${ }^{3}$ Department of Prosthodontics, Vidarbha Youth Welfare Society's Dental College and Hospital, Amravati, Maharashtra, India

${ }^{5}$ Department of Oral Medicine and Radiology, Maitri College of Dentistry and Research Centre, Durg, Chhattisgarh, India

${ }^{6}$ Department of Periodontics, Bharati Vidyapeeth Dental College Sangli, Maharashtra, India

Corresponding Author: Sanjeev Singh, Reader, Department of Prosthodontics, Chhattisgarh Dental College and Research Institute, Rajnandgaon, Chhattisgarh, India, Phone: +91-7389687333, e-mail: sanjeevsingh2124@gmail.com
}

the Flexural Strength of Autopolymerizing Resins. J Health Sci Res 2017;8(1):15-19.

\section{Source of support: Nil}

Conflict of interest: None

\section{INTRODUCTION}

Methacrylate resins are one of the most commonly used materials in dentistry because of their biologic, physical, esthetic, and manipulative properties. Methacrylate polymers are capable of providing an excellent balance of features and characteristics needed for use in oral environment. Despite the various methods used to initiate the polymerization of denture base resins, the conversion of monomers to polymers is never complete; some unreacted (residual) monomer is always present. ${ }^{1-3}$ It has been proved that high level of residual monomer decreases the strength of denture base resins. ${ }^{4}$ It is also documented that autopolymerized resins have higher percentage of residual monomer $(2-5 \%)$ than in heat cured polymers (0.2-0.5\%). 5,6 Autopolymerizing resins are commonly used in procedures like fabrication of temporary record bases, splints or stents, provisional restorations, orthodontic appliances, and repair of prosthesis. The strength of this material has always been a matter of concern for their long-term use. Several curing methods have been recommended to improve the overall quality of acrylic resin restorations. The methods include bench curing, curing under a coat of petroleum jelly, in monomer saturated atmosphere, and under controlled pressure in air and/or Luke warm water. ${ }^{7}$

But the search for newer methods with ease of operations for improving the strength to obtain more durable prosthesis is still on. Hence, this study was planned to evaluate the synergistic effect of variation in time and temperature at constant pressure for enhancing the overall strength of the appliances or prosthesis made using two autopolymerizing resins for their better utilization in dentistry.

\section{MATERIALS AND METHODS}

Materials selected for the study were:

- $\quad$ RR Cold Cure resin (DPI - Bombay Burmah Trading Corporation Ltd, 9-Wallace Street, Mumbai) - D1 


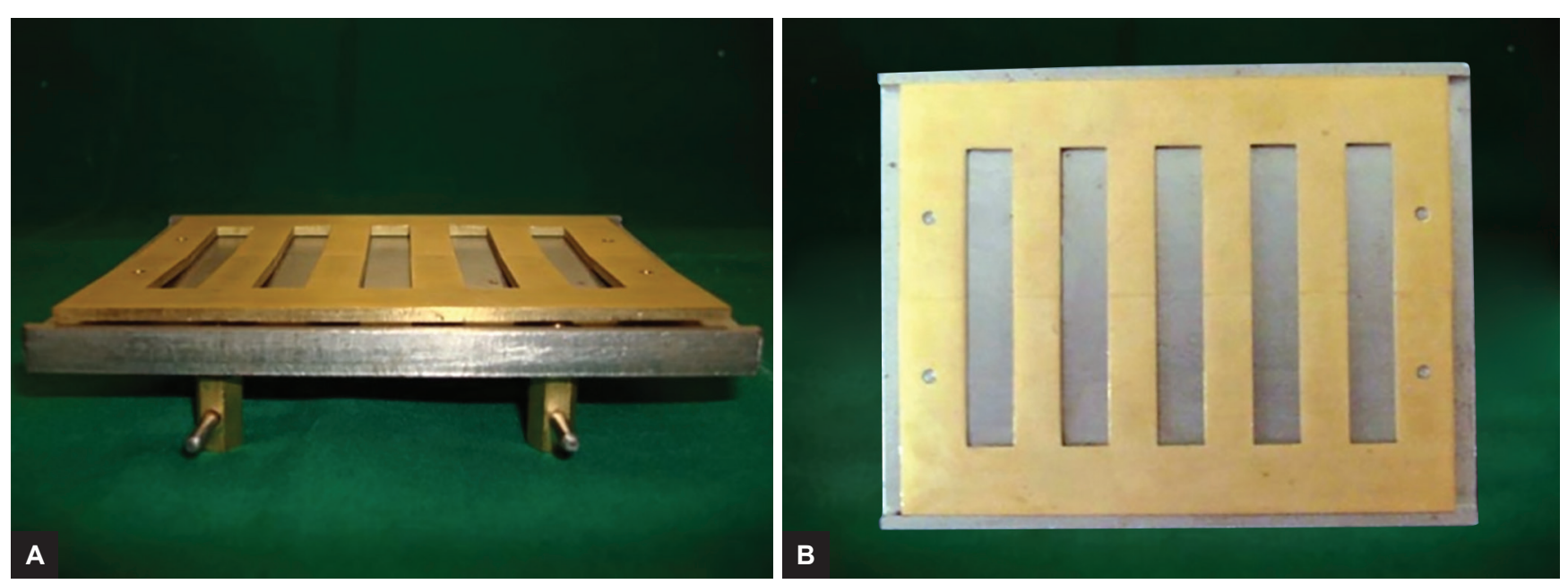

Figs 1A and B: Die used in the study

- RR-Rapid Repair Powder (Dentsply India Pvt. Ltd, Plot No. 9, Phase-I, Udyog Vihar, Gurgaon) - D2.

The materials were designated as D1 and D2.

\section{Methodology}

Test was done in accordance with American Dental Association (ADA) specification no. 12. A precise metal die was fabricated for making the acrylic resin samples to be used in the study (Figs 1A and B). Samples were prepared as under:

- Ten samples of materials D1 and D2 were prepared as control group and curing was carried out in open air at room temperature.

- Five samples for materials D1 and D2 were fabricated and subjected to altered conditions of time and temperature with constant pressure of 30 psi using custommade pressure pot as per the protocol of the study.

The details of sample size and groups are described in Table 1.

A brass die with five rectangular slots measuring $64 \mathrm{~mm}$ length, $10 \mathrm{~mm}$ width, and thickness of $2.5 \mathrm{~mm}$ was

Table 1: Details of sample size and groups

\begin{tabular}{|c|c|c|c|c|}
\hline Groups & Temperature & $\begin{array}{l}\text { Time } \\
\text { interval (in } \\
\text { minutes) }\end{array}$ & $\begin{array}{l}\text { No. of } \\
\text { samples } \\
\text { of } D 1\end{array}$ & $\begin{array}{l}\text { No. of } \\
\text { samples } \\
\text { of D2 }\end{array}$ \\
\hline Control & Room temperature & As required & 10 & 10 \\
\hline \multirow[t]{3}{*}{ Group 1} & $40^{\circ} \mathrm{C}$ & 5 & 5 & 5 \\
\hline & & 10 & 5 & 5 \\
\hline & & 15 & 5 & 5 \\
\hline \multirow[t]{3}{*}{ Group 2} & $50^{\circ} \mathrm{C}$ & 5 & 5 & 5 \\
\hline & & 10 & 5 & 5 \\
\hline & & 15 & 5 & 5 \\
\hline \multirow[t]{3}{*}{ Group 3} & $60^{\circ} \mathrm{C}$ & 5 & 5 & 5 \\
\hline & & 10 & 5 & 5 \\
\hline & & 15 & 5 & 5 \\
\hline \multirow[t]{3}{*}{ Group 4} & $70^{\circ} \mathrm{C}$ & 5 & 5 & 5 \\
\hline & & 10 & 5 & 5 \\
\hline & & 15 & 5 & 5 \\
\hline
\end{tabular}

custom-made for the fabrication of samples. To facilitate the easy removal of samples, the die was made into two halves, which could be reassembled to form one unit when positioned onto a metallic base with the help of two metallic projections (P) of $2.5 \mathrm{~mm}$ height and corresponding holes $(\mathrm{H})$ on either side for proper orientation.

Autopolymerizing resin was mixed for 10 seconds according to manufacturer's instruction to obtain the desired consistency and poured into the die. The entire assembly was then kept submerged in water in the custommade pressure pot (Fig. 2) having provision of automatic controls for temperature, time, and pressure. Curing was carried out at specific temperature and time as per the protocol of the study (Table 1), at a constant pressure of 30 psi. Postcuring, the samples were kept in distilled water for 48 hours before subjecting them for testing.

\section{Measuring the Flexural Strength}

The cured samples were then tested for flexural strength on universal testing machine using three-point bending test. For this purpose, a specially designed fixture of

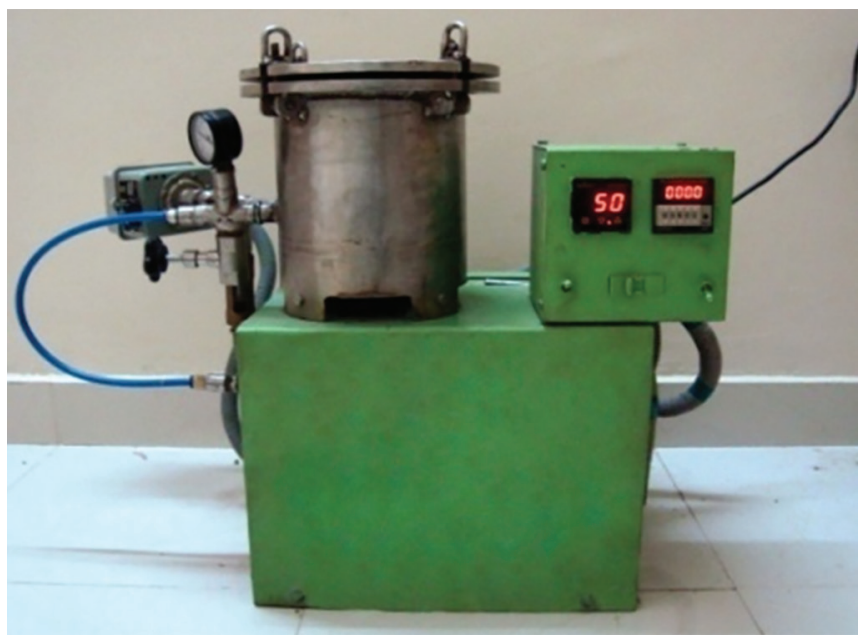

Fig. 2: Custom-made pressure pot 


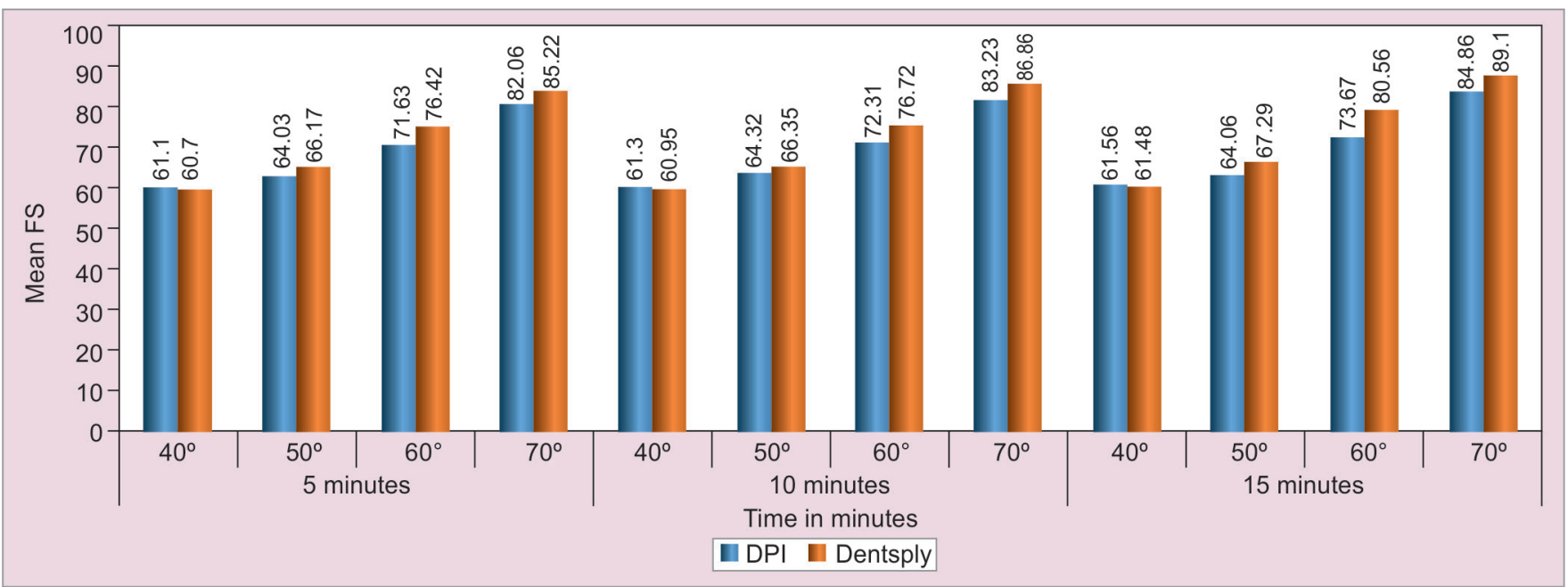

Graph 1: The mean flexural strength of materials D1 and D2, cured at different time and temperature, at a constant pressure

dimensions $50 \mathrm{~mm}$ length, $30 \mathrm{~mm}$ width, and height of $30 \mathrm{~mm}$ was used along with a customized " $\mathrm{T}$ "-shaped stress applicator rod to apply stress at the center of the specimen. The readings were recorded to calculate the flexural strength using the formula:

$$
\mathrm{FS}=3 \mathrm{pl} / 2 \mathrm{bd} \mathrm{d}^{2}
$$

where FS denotes the flexural strength, $\mathrm{p}$ is the peak load applied, 1 is the length of samples between two horizontal points " $R$," $b$ is the specimen width, $d$ is the specimen thickness.

\section{RESULTS}

Descriptive analysis of D1 and D2 materials at various temperatures and time intervals at constant pressure is listed in Table 2. There was a continuous increase in strength from $40^{\circ}$ to $70^{\circ} \mathrm{C}$ (Graph 1). Significant difference in strength was observed at 15 minutes in $50^{\circ} \mathrm{C}$ group and at each time interval of $60^{\circ} \mathrm{C}$ and $70^{\circ} \mathrm{C}$ for both the materials. There was no significant difference in flexural strength of above materials at $40^{\circ} \mathrm{C}$ and the control group.

Table 3 shows 'Student's unpaired t-test' for comparison between flexural strength of control groups of materials D1 and D2. No significant difference was noticed in strength for control group of both the materials. At $40^{\circ} \mathrm{C}$, for different time intervals, the values obtained were nonsignificant, for strength of both materials.

At $50^{\circ} \mathrm{C}$, highly significant values were noticed at 15 minutes time interval for D2 material, whereas the values remained significant at 5 and 10 minutes, suggesting increased strength of D2 material with increase in time interval at a constant pressure. The values of D2 material showed highly significant values when compared to D1 material at $60^{\circ}$ and $70^{\circ} \mathrm{C}$, with gradual increase in time, thus indicating the increase in strength of D2 material for each time interval.

Table 2: The descriptive statistics showing mean, standard deviation and standard error mean of specimen of D1 and D2 materials

\begin{tabular}{|c|c|c|c|c|c|c|c|c|c|}
\hline & \multicolumn{5}{|c|}{ D1 } & \multicolumn{4}{|c|}{$D 2$} \\
\hline & Time & Mean & $n$ & $\begin{array}{l}\text { Std. } \\
\text { deviation }\end{array}$ & $\begin{array}{l}\text { Std. error } \\
\text { mean }\end{array}$ & Mean & $n$ & $\begin{array}{l}\text { Std. } \\
\text { deviation }\end{array}$ & $\begin{array}{l}\text { Std. error } \\
\text { mean }\end{array}$ \\
\hline \multirow[t]{3}{*}{$40^{\circ}$} & 5 minutes & 61.10 & 5 & 0.57 & 0.25 & 60.70 & 5 & 1.31 & 0.58 \\
\hline & 10 minutes & 61.30 & 5 & 1.71 & 0.76 & 60.95 & 5 & 1.32 & 0.59 \\
\hline & 15 minutes & 61.56 & 5 & 0.88 & 0.39 & 61.48 & 5 & 0.91 & 0.40 \\
\hline \multirow[t]{2}{*}{$50^{\circ}$} & 5 minutes & 64.03 & 5 & 0.89 & 0.39 & 66.17 & 5 & 1.40 & 0.62 \\
\hline & 15 minutes & 64.06 & 5 & 0.97 & 0.43 & 67.29 & 5 & 0.74 & 0.33 \\
\hline \multirow[t]{3}{*}{$60^{\circ}$} & 5 minutes & 71.63 & 5 & 1.05 & 0.47 & 76.42 & 5 & 0.76 & 0.34 \\
\hline & 10 minutes & 72.31 & 5 & 0.47 & 0.21 & 76.72 & 5 & 1.37 & 0.61 \\
\hline & 15 minutes & 73.67 & 5 & 0.57 & 0.25 & 80.56 & 5 & 0.73 & 0.32 \\
\hline \multirow[t]{2}{*}{$70^{\circ}$} & 5 minutes & 82.06 & 5 & 0.59 & 0.26 & 85.22 & 5 & 0.84 & 0.37 \\
\hline & 10 minutes & 83.23 & 5 & 0.52 & 0.23 & 86.86 & 5 & 0.80 & 0.36 \\
\hline Control & & 56.52 & 10 & 0.51 & 0.16 & 56.63 & 10 & 0.58 & 0.18 \\
\hline
\end{tabular}


Table 3: A detailed comparison between two materials (Student's t paired test)

\begin{tabular}{|c|c|c|c|c|c|c|c|c|}
\hline \multirow[b]{3}{*}{ Group } & \multirow{3}{*}{$\begin{array}{l}\text { Time } \\
\text { intervals }\end{array}$} & \multicolumn{7}{|c|}{ t-test for equality of means } \\
\hline & & \multirow[b]{2}{*}{$t$-value } & \multirow[b]{2}{*}{$d f$} & \multirow[b]{2}{*}{$p$-value } & \multirow{2}{*}{$\begin{array}{l}\text { Mean } \\
\text { difference }\end{array}$} & \multirow{2}{*}{$\begin{array}{l}\text { Std. error } \\
\text { difference }\end{array}$} & \multicolumn{2}{|c|}{$\begin{array}{c}95 \% \text { confidence interval } \\
\text { of the difference }\end{array}$} \\
\hline & & & & & & & Lower & Upper \\
\hline \multirow[t]{3}{*}{$40^{\circ} \mathrm{C}$} & 5 minutes & 0.622 & 8 & $0.551 \mathrm{NS}, p>0.05$ & 0.40 & 0.64 & -1.08 & 1.88 \\
\hline & 10 minutes & 0.355 & 8 & $0.732 \mathrm{NS}, \mathrm{p}>0.05$ & 0.34 & 0.96 & -1.88 & 2.57 \\
\hline & 15 minutes & 0.140 & 8 & $0.892 \mathrm{NS}, \mathrm{p}>0.05$ & 0.08 & 0.56 & -1.23 & 1.39 \\
\hline \multirow[t]{3}{*}{$50^{\circ} \mathrm{C}$} & 5 minutes & 2.86 & 8 & $0.021 \mathrm{~S}, \mathrm{p}<0.05$ & -2.13 & 0.74 & -3.85 & -0.41 \\
\hline & 10 minutes & 3.56 & 8 & $0.007 \mathrm{~S}, \mathrm{p}<0.05$ & -2.03 & 0.57 & -3.35 & -0.71 \\
\hline & 15 minutes & 5.92 & 8 & $0.000 \mathrm{HS}, \mathrm{p}<0.0001$ & -3.23 & 0.54 & -4.49 & -1.97 \\
\hline \multirow[t]{3}{*}{$60^{\circ} \mathrm{C}$} & 5 minutes & 8.23 & 8 & $0.000 \mathrm{HS}, \mathrm{p}<0.0001$ & -4.78 & 0.58 & -6.12 & -3.44 \\
\hline & 10 minutes & 6.77 & 8 & $0.000 \mathrm{HS}, p<0.0001$ & -4.41 & 0.65 & -5.91 & -2.90 \\
\hline & 15 minutes & 16.46 & 8 & $0.000 \mathrm{HS}, p<0.0001$ & -6.88 & 0.41 & -7.85 & -5.92 \\
\hline \multirow[t]{3}{*}{$70^{\circ} \mathrm{C}$} & 5 minutes & 6.82 & 8 & $0.000 \mathrm{HS}, p<0.0001$ & -3.16 & 0.46 & -4.23 & -2.09 \\
\hline & 10 minutes & 8.38 & 8 & $0.000 \mathrm{HS}, \mathrm{p}<0.0001$ & -3.62 & 0.43 & -4.62 & -2.62 \\
\hline & 15 minutes & 11.84 & 8 & $0.000 \mathrm{HS}, \mathrm{p}<0.0001$ & -4.20 & 0.35 & -5.02 & -3.38 \\
\hline \multicolumn{2}{|c|}{ Control group } & 0.425 & 18 & $0.67 \mathrm{NS}, p>0.05$ & -0.10 & 0.24 & -0.62 & 0.41 \\
\hline
\end{tabular}

\section{DISCUSSION}

It is a well-known fact that polymerization of chemically activated resin remains incomplete due to the presence of unreacted monomer, hence, the strength of material is questionable. Moreover, its wide application in dentistry demands superior physical and mechanical properties. The decreased strength of these resins is attributed mainly to the presence of unreacted monomer which acts as plasticizer, resulting in reduced flexural strength.

Many attempts have been advocated to reduce the amount of residual monomer and increase the strength of these resins, like processing of the resin in water under pressure to reduce porosity and increase the strength. 8,9 Few researchers have favored the effect of temperature, rather than pressure, for increased strength of resin. ${ }^{10,11}$ Also soaking resin in water helps to decrease the amount of residual monomer, which ultimately increases the strength of the resin. ${ }^{12}$ Though water temperature seems to hasten polymerization, the temperature has not been adequately defined and also the influence of time on the curing under specific pressure and temperature is not being clearly mentioned in the literature. Hence, this study was conducted to evaluate the effect of increased temperature, time, at a constant pressure.

In the present study, it was observed that there is gradual increase in strength with rise in temperature from $40^{\circ} \mathrm{C}$ to $70^{\circ} \mathrm{C}$ at a constant pressure. Highest strength of the resin was obtained with the samples cured at $70^{\circ} \mathrm{C}$, $40^{\circ} \mathrm{C}$, and $50^{\circ} \mathrm{C}$ showed not much difference in the flexural strength, but definitely had increased strength than the samples cured in open air. In each group the strength obtained at 15 minutes was more than that of 5 and 10 minutes. The results obtained in the study are comparable with the results obtained by various researchers which showed increased strength at higher temperatures. ${ }^{8,9,11}$
The increase in strength can be attributed to the more complete polymerization at higher temperatures as heat activates the chemical reaction and the number of free radicles is lowered. The curing carried out inside the pressure unit in the pressure environment also has an effect on reducing porosity from inside the resin, which in turn enhances the strength. Reduction in the amount of residual monomer also helps in increase of strength of the resin. And it also has the added advantage of making the resin more biocompatible by reducing the tissue irritation caused by the monomer. Hence, it can be recommended to cure the resin under water at $70^{\circ} \mathrm{C}$ at a constant pressure for minimum of 10 minutes to obtain the desired strength of the autopolymerizing resins.

\section{Clinical Implication}

The results of this study reveal the advantage of placement of autopolymerizing resins at high temperatures and a constant pressure so as to provide sufficient strength and long-term durability of the resins. Based on the results of this study, placement of resin in hot water at controlled pressure will definitely enhance the strength of the resin and hence, it should be followed routinely in practice to provide more acceptable prosthesis.

\section{CONCLUSION}

The result of this study could provide with the data that will help the clinician and laboratory personale for better manipulation and usage of autopolymerizing resins. Within the scope and limitations of the study, the following conclusions were made as per the findings:

- Curing the autopolymerizing resin in hot water under pressure is an effective means of increasing the strength of the resin. 
- The resin samples cured at $70^{\circ} \mathrm{C}$, for 15 minutes under pressure of $30 \mathrm{psi}$, produced excellent result with increased flexural strength as compared to the samples of control group.

- Time interval of 10 minutes is sufficient to provide adequate strength to the autopolymerizing resin sample, when compared with samples of control group.

- Among the group of two materials used in the study, D2 material has showed more strength than D1 at temperatures of $60^{\circ} \mathrm{C}$ and $70^{\circ} \mathrm{C}$, but the strength is almost the same at room temperature in open air.

Processing of resin as per the method mentioned in the study can be employed routinely in laboratory protocol to improve the strength and durability of the prostheses fabricated with autopolymerizing resin.

\section{REFERENCES}

1. Valittu PK, Ruyter IE, Buykuilmaz S. Effect of polymerization temperature and time on the residual monomer content of denture base polymer. Eur J Oral Sci 1998 Feb;106(1): 588-593.

2. Vallittu PK, Meittinen V, Alakuijala P. Residual monomer content and its release into water from denture base materials. Dent Mater 1995 Nov;11(6):338-342.

3. Lee SY, Lai Yl, Hsu TS. Influence of polymerizing conditions on the monomer elution and microhardness of autopolymerising polymethyl methacrylate resin. Eur J Oral Sci 2002 Apr;110(2):179-183.

4. Dogan A, Bek B, Cevik NN, Usanmaz A. The effect of preparation conditions of acrylic denture base materials on the level of residual monomer, mechanical properties and water absorption. J Dent 1995 Oct;23(5):313-318.

5. Ruyter IE, Oysaed H. Conversions in denture base polymers. J Biomed Mater Res 1982 Sep;16(5):741-754.

6. Fletcher AM, Purnaveja S, Amin WM, Ritchie GM, Moradians $\mathrm{S}$, Dodd AW. The level of residual monomer in self-curing denture-base materials. J Dent Res 1983 Feb;62(2):118-120.

7. O'Tool TJ, Furnish GM, Von Fraunhofer JA. Linear distortion of acrylic resin. J Prosthet Dent 1985 Jan;53(1):53-55.

8. Smith DC, Lord JL, Bolender CL. Complete denture relines with autopolymerizing acrylic resin processed in water under air pressure. J Prosthet Dent 1967 Aug;18(2):103-114.

9. Donovan TE, Hurst RG, Campagni WV. Physical properties of acrylic resin polymerized by four different techniques. J Prosthet Dent 1985 Oct;54(4):522-524.

10. Gegauff AG, Pryor HG. Fracture toughness of provisional resin for fixed prosthodontics. J Prosthet Dent 1987 Jul;58(1):23-29.

11. Ogawa T, Tanaka M, Koyano K. Effect of water temperature during polymerization on strength of autopolymerizing resin. J Prosthet Dent 2000 Aug;84(2):222-224.

12. Bayraktar G, Guvener B, Bural C, Uresin Y. (2005) Influence of polymerization method, curing process, and length of time of storage in water on the residual methyl methacrylate content in dental acrylic resins. J Biomed Mater Res B Appl Biomater 2006 Feb;76(2):340-345. 